\title{
Multimodality in Indomie Advertisement
}

\author{
Dewi Yulia Wati, Universitas Airlangga
}

\begin{abstract}
Every product advertises with its own way involving the excellence and uniqueness of the product advantages over others which presents their intention to consumers. One of Indonesia's leading brands is Indomie, famous for instant noodle products with unique taste of Indonesian culinary in product variants. The purpose of this paper is to examine the hidden meaning within Indomie advertisement 'Jagonya Soto' posted on their official Facebook page as a main source. This study used qualitative method and Kress and van Leeuwen's social semiotics theories about multimodality with three metafunctions, namely representational, interpersonal, and compositional. The result of this study shows that the representational metafunction of the advertisement contains the map of Indonesia, picture of Soto variants, Indomie logo itself and the writing of the advertisement theme of "Jagonya Soto". The interpersonal metafunction has their main aspects: visual demand, frontal angle and medium horizontal angle in order to easily attract the audience attention. Then, compositional metafuntion of this advertisement includesthe size and blue as dominant colour of the advertisement.
\end{abstract}

Keywords: multimodality; indomie advertisement; representational metafunction; interpersonal metafunction; compositional metafunction

\section{Introduction}

As the time goes by, communication and technology are interdependent with each other that became the medium for conveying the veiled intentions of a particular discourse. Communication not only relies on verbal but also non-verbal communication as well. One form of communication that we often encounter is a picture or poster, which in its delivery depends on visual communication. Harrison (2003: 46) has been stated that the emergence of images as an important model in communication nowadays is a sign that readers are no longer dependent on the text or verbal. to know the meaning of something. One picture presented by the media can give its own interest to the reader so that the producer decomposes without needing many sentences.

Advertisement is one of communication forms delivering product messages from producers to consumers. Generally, advertising appears in the form of multimodal discourse because it involves texts and visual graphics such as colours, typography, illustrations and photographs (Young \& Fitzgerald: 101). In order to understand the meanings within advertisements, we read and interpret all of the semiotic resources involved. To completely fulfil its function, an advertisement has to eye-catching and entertaining not only serving the purpose of supporting sale activity, in the long run, advertisement aimed to build the relationship between producer and consumer or audience (Febrianti, 2013: 300). In brief, advertising is highly influenced by the social and cultural context and situation where they are produced and/ or published.

One of leading brand in Indonesia, Indomie as the food brand for instant noodle has many product variants. This brand won many awards from year to year, recently won the best noodles in the "Regional Tier Awards 2018" category (idntimes.com accessed on $2^{\text {nd }}$ June 2018). This is because Indomie is still the best brand that covers certain geographical areaInstant noodles themselves are relatively affordable, easy to serve and durable which makes Indomie growing rapidly along with the receipt of instant noodles in Indonesia. Based on the official webpage Indomie.com (accessed on June 2, 2018), Indomie's first introduced product was Indomie Kuah Rasa Kaldu Ayam which was then in accordance with the taste of the tongue of Indonesian society. Then in 1982, Indomie product sales increased significantly with the launch of Indomie Kuah Rasa Kari Ayam variant. The peak in 1983, then Indomie again 
launched new variants Indomie Mi Goreng following by new variants of Soto. The advertisement of the products is easily found in various media mass such as television, magazine, radio. The product promotion uses social medias such as Instagram, Twitter, Facebook also easily found nowadays. Therefore, this study aims to analyze the hidden meaning within Indomie poster advertisement 'Jagonya Soto' posted on their official Facebook page as the Figure 1, following below.

Figure 1. Official facebook page

(source: https://web.facebook.com)

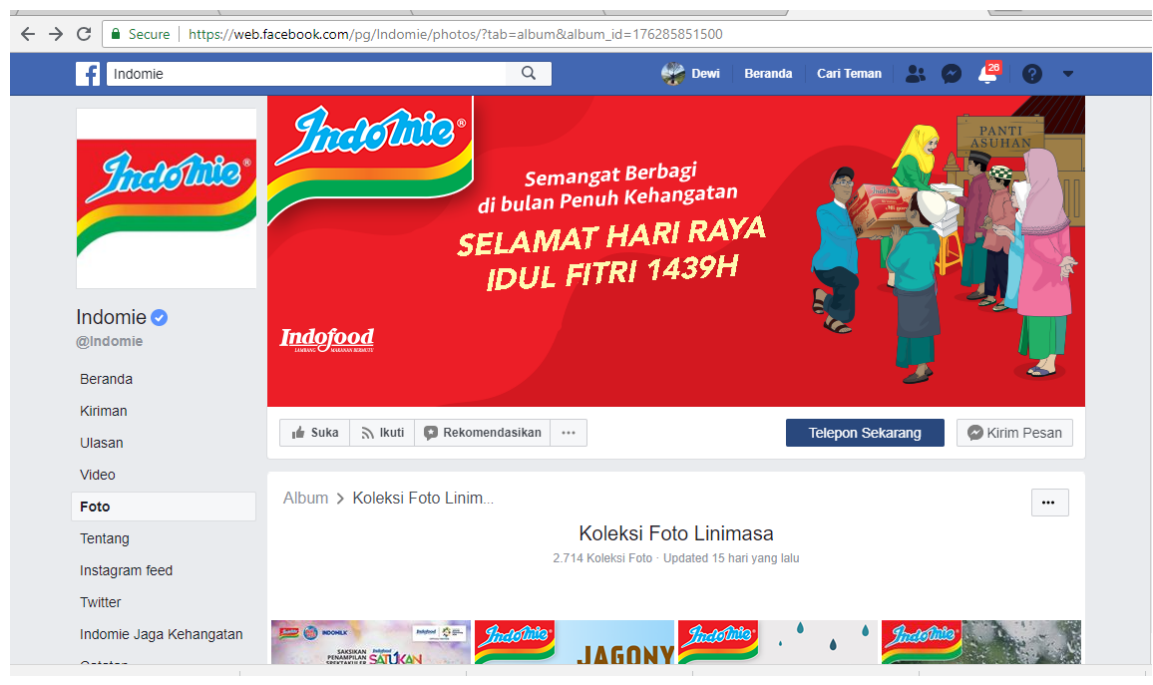

\section{Literature review}

Nowadays, many advertisement can be seen in various media both offline and online. As the medium for presenting the product to consumers, manufacturer tries to make advertisement as interesting as possible to attract audience attention. According to Kress and Leeuwen (2006: 154), the emergence of images or picture as a medium of communication on various online websites shows the credibility of the producers. Advertisements, both print and electronic advertisements on various online-based social media such as Facebook, YouTube, and Twitter are text which has the complexity of meaning that we can easily encounter in everyday life. Complexity of meaning refers not only to how convey a message in advertisement through text but also visual elements. To be able to decompose the complexity of elements contained in advertising, it is necessary to analyze the modality using semiotic components which was applied by Kress and van Leeuwen.

Semiotics has identified the need to develop holistic and socially aware theories and descriptions of semiosis, applicable to all signs and sign systems but also capable of taking into account the specific characteristics of different semiotic phenomena. Barthes (in Cobley, 2006: 690) argued that semiotics leads to a particular discourse when relations between markers and markers produce a sign. The broad social semiotic theoretical framework has contributed significantly to the development of the critical discourse studies approach such as Fairclough (in 1992), with its emphasis on the role of discourse in social empowerment and change. It has also formed the basis of work within an emerging tradition of multimodal studies which has itself been informed throughout its development by critical discourse perspectives. O'Halloran et.al. has been stated:

"The study of multimodal discourse - discourse involving the interaction of multiple semiotic resources such as (spoken and written) language, gesture, dress, architecture, proximity (and in film for example) lighting, movement, gaze, camera angle, etc received three major impetuses during the twentieth century." (2011:2) 
Social semiotics is able to say something about the function of each modes in the multimodal text (image, number, colour, writing and facial expression), about the relation of these modes to each other, and about the main entities in the text. (Kress, 2010: 59) Multimodal discourse analysis is the study of the intersection and interdependence of various modalities of communication within a given context as Snyder stated (2009:1). The notion ofsemiotic resourcein multimodal social semiotics is critical. Van Leeuwen (2005: 3) explains "it originated in the work of Halliday who argued that the grammar of a language is not a code, not a set of rules for producing correct sentences, but a resource for making meanings". In brief, multimodality is the mix of modes which is nearly always present in communication especially visualization communication. According to Renkema (2004: 76), one of aspect of multimodality which received special attention in discourse studies is the co-deployment of the visual element in written discourse (a text with a diagram, a picture and so forth).

Digital technology provides a common platform for semiotic resources to combine and unfold in new and innovative ways. Therefore, digital technology is multimodal social semiotic technology. However, how is digital technology actually impacting on disciplines which embrace the new technology foe examples mathematics and science. The use of visualisation processes and computer graphics in mathematics and science for the interpretation of complex data sets relate to human capabilities of seeing visual patterns. Watson and Walatka (1994: 7), argued that visual analysis techniques are particularly well suited to the human cognitive capabilities, more emphasis has been placed on visual analysis tools for understanding computer simulations of complex phenomena". It has been stated that humans cannot process the information at the same rate when presented with the symbolic data generated by supercomputer simulations or high-powered scientific instruments (O'Halloran, 2009:6). Colonna (1994: 184) states:

"vision is the most highly developed of our human senses for reception, isolation and understanding of information about our environment. Vision provides a global perception of coloured shapes against a changing, moving, and noise-filled background. The idea of using the eye as the main tool in the analysis of numerical results is therefore quite natural."

The means for exploring the behaviour of the system remains multisemiotic such as symbolic, visual and linguistic elements. However, the potential meaning of those semiotic resources expanded in the dynamic realm of computer-based visualization such as colour, texture, size, shape, point of view, and so forth. Machin (2007: 9) states that multimodal approach systematically describes the range of choices available and how they are used in context. It considers the way signs are used in combination. In conclusion, Kress \& Leeuwen argued that there are three major for analysing multimodality discourse inspired by Halliday. It is called metafunctions, representation, interpersonal, compositional metafunction. Representational metafunction involves sociologically and linguistically influential elements. Interpersonal metafunction presents two functions; to create a visual of the advertised product, and an invitation to the reader to feel what the picture object conveys. Then, compositional metafunction includes value of information applicable to the choice of semiotics mark selected by the producer, the size of the advertisement picture, the colours used in the picture and so on.

\section{Methodology}

This study uses descriptive qualitative analysis to examine the data. According to Moleong (1994: 5-6), research methods using data containing word, oral or image descriptions of each individual, phenomena or events of various groups that can be used by researchers is categorized as qualitative research. Since this study lies under qualitative-based research, the data retrieved directly from Facebook, Indomie official homepage posted on April 2018. Then, the data downloaded in PNG format and later copied to Microsoft Word for further analysis. Moreover, Kress and Leeuwen (in Harrison, 2003: 50) provide methods for processing images using three meta-semiotic steps consisting representational, interpersonal and composition functions which can be used to analyze the aim of this study. 


\section{Result and Discussion}

To analyze social semiotics, the thing to note from the Represented Participant (RP) in the picture of advertisement is the potential meaning created which used to analyze representational metafunction. Leeuwen (2008: 23) explains that the question that researchers need to issue is what can be said rather than what must be said from the picture. RP selection is sociologically and linguistically influential. Sociologically RP can refer to two possibilities, the agent or patient. In the advertisement poster Indomie 'Jagonya Soto' version, which is present in Figure 2 below directly represents several objects, they are the map of Indonesia and various products of Indomie Soto as non- human objects, as well as Indomie logo itself and there is a verbal element, namely the writing of the advertisement theme of "Jagonya Soto". The picture of product Soto variants presents the taste of the product originated Indonesian typical dish especially Soto variants in this advertisement such as Soto Padang, Soto Lamongan, Soto Banjar, Soto Medan etc. The map represents that the products are available in Indonesia and the tastes are inspired by Indonesian typical culinary.

Figure 2. The maps

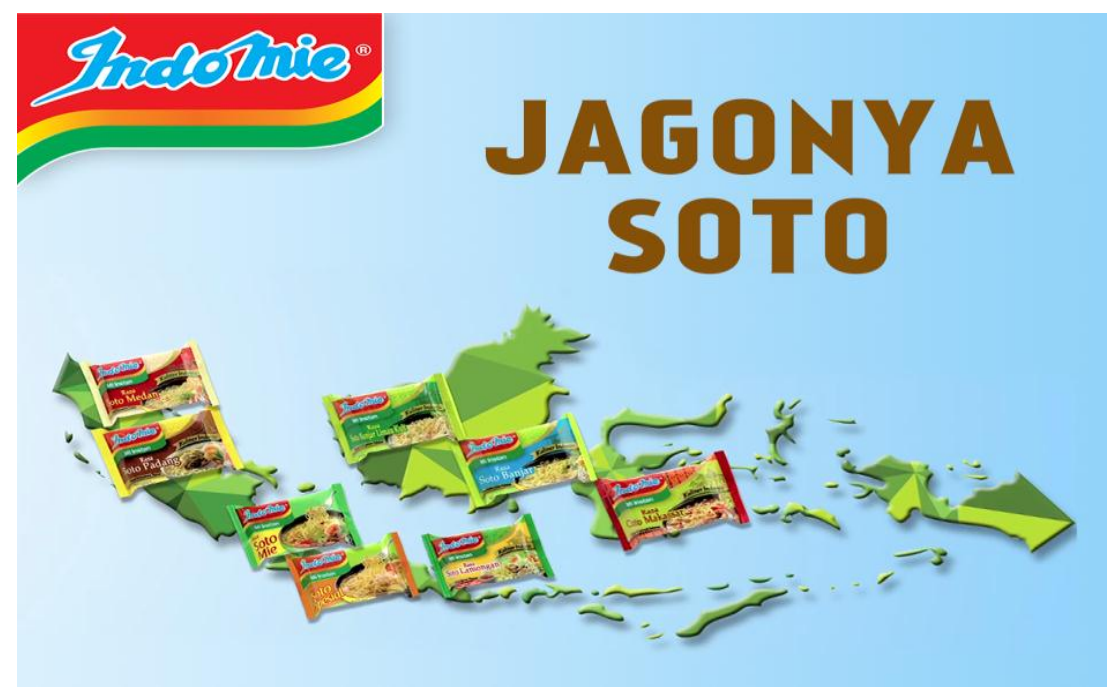

The poster contains one phrase only "Jagonya Soto" as the theme of the product advertisement. The presence of other objects such as in particular the map of Indonesia and product variants of Indomie Soto in this advertisement is an attempt to accentuate the visual imagination of Indomie Soto in this advertisement is an attempt to accentuate the visual imagination of the effects constructed from the advertised product. Figure 2 is the combination of three main aspects, namely visual demand, frontal angle and medium horizontal angle. In interpersonal metafunction, visual demands have two functions; first function is to create a visual of the advertised product and second one is an invitation to the reader to feel what the picture object conveys (Kress \& van Leeuwen, 2006: 122). Indonesia map displayed in this poster is an object that is considered by the producers have the power to make readers pay attention to it because people are familiar with the map of Indonesia itself. The advertisement uses frontal angle and horizontal angle medium which according to Kress and Leewen (2006: 143), this suggests that the producer or manufacturer has the intention to show that the image present in the ad is part of the reader in everyday life.

At this stage of compositional metafunction, researcher relates the relationship between two previous metafunctions, both representational and interpersonal to know the message to be conveyed by the manufacturer. The placement of picture objects in this advertisement is important because the producers expect to attract the reader attention by placing the map and products in the centre of poster to easily catch the audience attention. The composition of the image elements on this Facebook homepage represent the purpose of the manufacturer. In this 
compositional metafuntion is analyzed the value of information applicable to the choice of semiotics mark selected by the producer, the size of the advertisement picture, the colours used in the picture, as well as the modalities of this advertisement. The first dominant colour in the poster is blue placed on the background of the picture and this is the same colour as the writing 'Indomie' of the Indomie product logo. And the second dominant colour is green found in Indonesia map as same as the bottom colour of the logo on the upper left corner of the poster. Furthermore, the size of picture is medium centred- position for the map and products placed to attract the reader attention. Then, the writing of the advertisement theme 'Jagonya Soto' has big size to emphasize that the advertised product is Soto variants while the logo placed on upper left corner in medium size of 1:12 scale.

Social media, such as Facebook has become a catalyst of the development of social media so new potential consumers more easily access a variety of product advertisements. Moreover, this causes consumers no longer choose products based on the quality of the material only, but from the way manufacturers advertise their products interestingly. From the three metafunctions can be seen that the focus of this version advertisement is variant of Soto flavours of Indomie products. The middle position of product pictures and the advertisement theme writing on the top right that emphasizes the product information to be conveyed. The map of Indonesia is a representation of these products have a distinctive taste of Indonesian cuisine and can be found in various regions of Indonesia. The discourse is an effort to advertise their products by introducing the various culinary tastes of the Indonesian archipelago in their packaging products.

\section{Conclusion}

From the discussion above, it can be concluded that the representational metafunction of the advertisement contains the map of Indonesia and various products of Indomie Soto as nonhuman objects, as well as Indomie logo itself and there is a verbal element, namely the writing of the advertisement theme of "Jagonya Soto". In other hand, the interpersonal metafunction has their main aspects, namely visual demand, frontal angle and medium horizontal angle in order to easily attract the audience attention. Furthermore, compositional metafuntion of this advertisement includes the size of the advertisement picture, the colours used in the picture, as well as the modalities of this advertisement which shows that the poster uses blue as dominant colour and object placed as attractive as it is. In conclusion, the focus of the pester advertisement of Indomie "Jagonya Soto' version is product variants of Soto itself. The product pictures are displayed along with the map of Indonesia which represents the products inspired by the taste of Indonesian typical culinary. Especially, in this advertisement is Soto, one of Indonesian dish which can be found in various regions of Indonesia but with different taste and ingredients.

\section{References}

Colonna, J. 1994. Scientific display: a means of reconciling artists and scientist. In Clifford A. P., \& Stuart K. T (eds.). Frontiers of Scientific Visualization. New York: John Wiley \& Sons, pp. 181-212.

Febrianti, Yusnita. 2013. Language policy and planning: what are the issues? multimodal discourse analysis in Indonesian print advertisement. Salatiga: UKS, 298-312.

Harrison, C. 2003. Visual social semiotics understanding how still images make meaning. Technical Communication, 50(1), 46-60.

Kress, Gunther R., \& Van Leeuwen, T. 2006. Reading images the grammar of visual design $\left(2^{\text {nd }}\right.$ ed). New York: Routledge.

Kress, Gunther R. 2010. Multimodality: a social semiotic approach to contemporary communication. USA: Routledge.

Leeuwen, T. Van. 2005. Introducing social semiotics (1st ed.). New York: Routledge.

Leeuwen, T. Van. 2008. Discourse and practice: new tools for critical discourse analysis. New York: Oxford University Press. 
Machin, David. 2007. Introduction to multimodal analysis. London: Bloomsbury Publishing Plc.

Moleong, L. J. 1994. Metodologi penelitian kualitatif. Bandung: PT. Remaja Rosdakarya.

O'Halloran, K. L. 2009. Interdisciplinary perspectives on multimodality: theory and practice. Multimodal analysis and digital technology. Campobasso: Palladino.

O'Halloran, K. L. et.al. 2011. Multimodal discourse: critical analysis within an interactive software environment. Campobasso: Palladino.

Renkema, Jan. 2004. Introduction to discourse studies. USA: John Publishing Company.

Snyder, J. 2010. Applying multimodal discourse analysis to studyimage-enabled communication.

Watson, Velvin, Walatka, Pamela P. 1994. Visual analysis of fluid dynamics. In David F. R., Rae, A., \& Earnshaw, R. A (eds.). State of the Art in Computer Graphics: Aspects of Visualization. New York: Springer-Verlap, pp. 7-18.

Young, L. \& Fitzgerald. 2006. The Power of Language. London: Equinox.

Idntimes. Available at webpage https://www.idntimes.com/business/economy/reza-iqbal/9brand-terbaik-di-indonesia. (Accessed on June 2, 2018).

Indomie. Available at webpage https://web.facebook.com/Indomie. (Accessed on June 2, 2018). 